\title{
Atrophoderma of Pasini and Pierini: An unusual presentation
}

\section{Romita Bachaspatimayum, Nandita Bhattacharjee, Priyanka Das}

\author{
Department of Dermatology, Venereology and Leprology, Regional Institute of Medical Sciences, Imphal, Manipur, India
}

Corresponding author: Dr. Nandita Bhattacharjee, E-mail: piyubhattacharjee@gmail.com

\begin{abstract}
Atrophoderma of Pasini and Pierini is a rare variant of dermal atrophy with unknown etiology. It is characterised by one or more asymptomatic, bilaterally symmetrical, well defined, hyperpigmented, non sclerotic patches with an abrupt edge, distributed mostly over the trunk. We report here a 19 year old female presenting with single, asymptomatic, round, hypopigmented, non-indurated, slightly depressed patch over lateral aspect of left arm. The histopathological examination revealed orthokeratotic epidermis and degenerated loosely separated collagen bundles in the mid and reticular dermis. A diagnosis of atrophoderma of Pasini and Pierini was made. The patient was treated with oral hydroxychloroquine $200 \mathrm{mg}$ twice daily. There was significant improvement after 2 months of treatment.
\end{abstract}

Key words: Atrophoderma of Pasini and Pierini; Hypopigmented patch; Hydroxychloroquine

\section{INTRODUCTION}

Atrophoderma of Pasini and Pierini is a rare disorder of idiopathic dermal atrophy. It was first reported by Pasini [1] in 1923 as progressive idiopathic atrophoderma and later defined by Pierini and Vivoli [2] in 1936. In 1958, Canizares et al.[3] evaluated the findings of Pierini and renamed it as idiopathic atrophoderma of Pasini and Pierini. They also believed that it differed adequately from morphea. It is characterized by asymptomatic, round to oval, bluish gray to brown, non-indurated patches with mild depression and "cliff drop" margin. Here we report a case of atrophoderma of Pasini and Pierini in a young female.

\section{CASE REPORT}

A 19 year old female presented with single asymptomatic, slowly progressive, hypopigmented, slightly depressed patch over left arm for last one year. There was no previous history of any trauma or tick bite. Her medical history was unremarkable. On clinical examination, single well defined, round, hypopigmented patch measuring $1 \mathrm{~cm} \times 1 \mathrm{~cm}$ was present over lateral aspect of left arm (Fig. 1). The patch was slightly depressed than the level of surrounding skin with "cliff drop" margin. There was no tenderness or induration.

Laboratory investigations including complete blood count, random blood sugar, liver function test, renal function test and urine routine examination were all within normal limits, but her erythrocyte sedimentation rate was raised $\left(45 \mathrm{~mm} / \mathrm{l}^{\text {st }}\right.$ hour $)$. Anti nuclear antibody and anti-ds DNA level were within normal limit. Histopathological examination from skin biopsy specimen showed orthokeratotic epidermis and degenerated loosely separated collagen bundles in the mid and reticular dermis (Fig. 2). Based on the clinical and histopathological findings, a diagnosis of atrophoderma of Pasini and Pierini was made. The patient was treated with oral hydroxychloroquine $200 \mathrm{mg}$ twice daily. After 2 months of treatment, there was notable improvement in the depressed depth of the lesion (Fig. 3).

Prior to the study, patient gave written consent to the examination and biopsy after having been informed about the procedure.

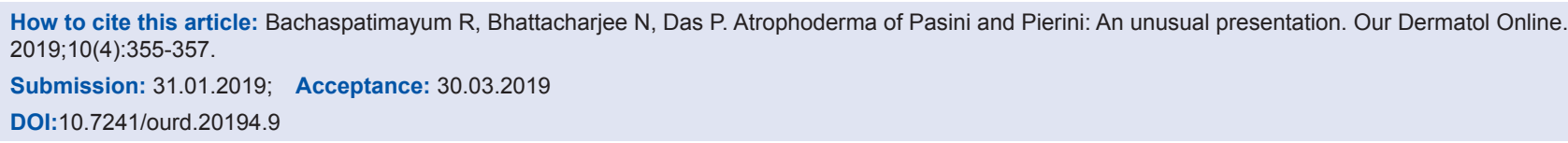




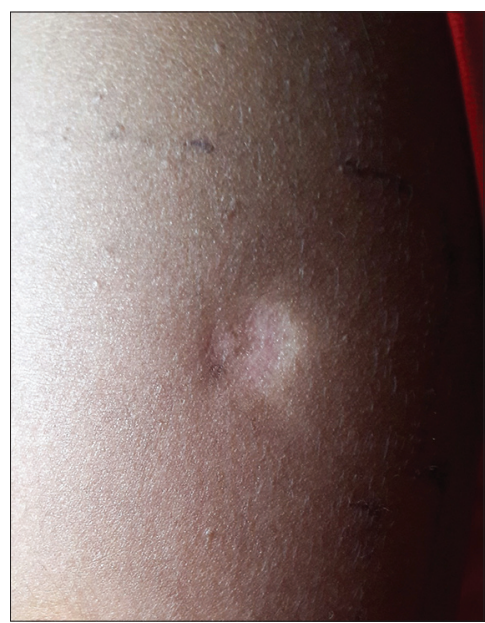

Figure 1: Single, well demarcated, hypopigmented, depressed patch over left arm.

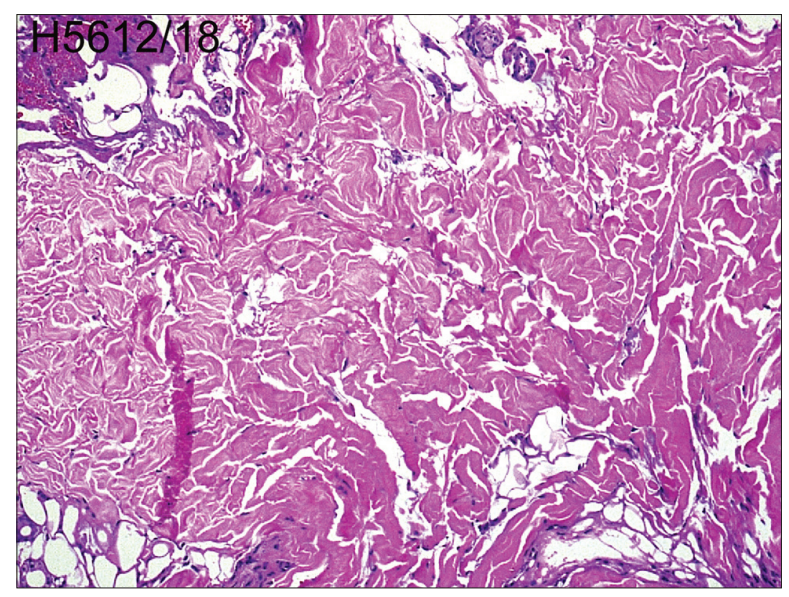

Figure 2: Degenerated loosely separated collagen bundles in the mid and reticular dermis ( $\mathrm{H} \& \mathrm{E}, 40 \mathrm{X})$.

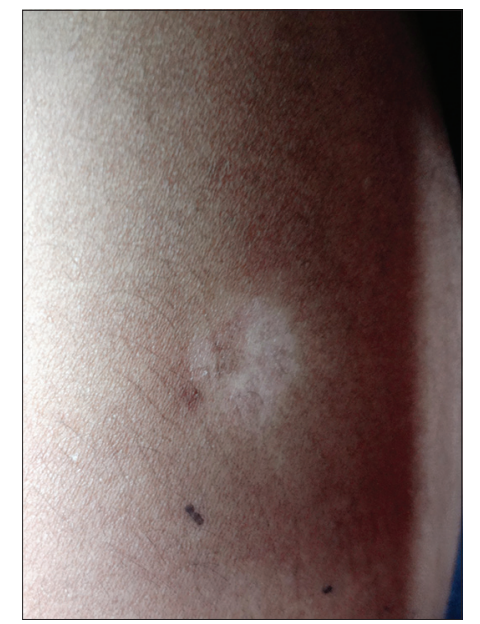

Figure 3: Significant improvement in term of depressed depth of the lesion after 2 months of treatment with oral hydroxychloroquine.

\section{DISCUSSION}

Atrophoderma of Pasini and Pierini is an uncommon form of dermal atrophy which usually follows a benign course. There is a female preponderance seen in various literatures $[3,4]$. Onset is insidious in adolescents and young adults, but few congenital cases are also reported $[5,6]$.In our case, the patient was female with age of onset at 18 years. The etiopathogenesis of atrophoderma of Pasini and Pierini is puzzling. In most of the cases, it is considered as an idiopathic atrophy of dermis. The role of Borrelia burgdorferi infection in the pathogenesis had been suggested by some authors [7]. In our case, there was no history of mountain climbing or tick bite.

The lesions are usually asymptomatic, slowly progressive, either single or multiple, sharply demarcated patches of variable sizes and oriented along the cleavage lines. Frequently, these lesions are symmetrically and bilaterally distributed on the trunk and less commonly on the extremities. However, unilateral and zosteriform pattern has also been reported [3]. In our patient, single patch was present on left arm. Most commonly, the lesions are round to ovoid, bluish gray to hyperpigmented, soft, non-indurated and slightly depressed than the level of surrounding skin with an abrupt edge or "cliff-drop" border. These patches are classically described as "footprints in the snow" or "swiss-cheese like". In our patient, the patch was hypopigmented which is consistent with the finding of Saleh et al.[4] in which majority of the lesions were hypopigmented (56\%).

The histopathological features of atrophoderma of Pasini and Pierini are often minimal and non-specific. The epidermis is usually normal or slightly atrophic. There may be presence of mild lymphocytic infiltration and normal or hyalinized collagen in dermis [5]. In our case, there was presence of degenerated loosely clumped collagen in mid and reticular dermis.

There is ongoing debate on whether atrophoderma of Pasini and Pierini is a variant of localized scleroderma or a distinct entity. However, in 1958 Canizares et al. [3] classified idiopathic atrophoderma of Pasini and Pierini as a separate entity based on the early onset, longer course, absence of induration and distinct histopathological features like absence of dermal sclerosis, inflammation and no loss of appendegeal structures as compared to morphea.

Till date, no effective treatment is available for atrophoderma of Pasini and Pierini. However, some patients may respond to phototherapy, oral antibiotic and oral hydroxychloroquine [8]. Our patient 
responded significantly to oral hydroxychloroquine and there was no new lesion.

\section{CONCLUSION}

This case is reported due to the unusual presentation of hypopigmented patches. Although benign in nature, atrophoderma of Pasini and Pierini should be differentiated from morphea to reduce unnecessary treatment burden of the patients.

\section{Consent}

The examination of the patient was conducted according to the Declaration of Helsinki principles.

\section{REFERENCES}

1. Pasini A. Atrofodermiaidiopathicaprogressiva. G Ital Dermatol. 1923;58:785.

2. Pierini L, Vivoli D. Atrofodermiaidiopathicaprogressiva (Pasini).
G Ital Dermatol 1936;77:403-9.

3. Canizares O, Sachs PM, Jaimovich L, Torres VM. Idiopathic atrophoderma of Pasini and Pierini. AMA Arch Derm 1958;77:42-58.

4. Saleh Z, Abbas O, Dahdah MJ, Kibbi AG, Zaynoun S, Ghosn S Atrophoderma of Pasini and Pierini: a clinical and histopathological study. J CutanPathol. 2008;35:1108-14.

5. Orteu $\mathrm{CH}$. Morphea and allied scarring and sclerosing inflammatory dermatoses. In: Griffiths C, Barker J, Bleiker T, Chalmers R, Creamer D, editors. Rook's Textbook of Dermatology. $9^{\text {th }}$ ed. UK: Wiley- Blackwell; 2016. p. 57.1-57.29.

6. Handler MZ, Alshaiji JM, Shiman MI, Elgart GW, Schachner LA. Congenital idiopathic atrophoderma of Pasini and Pierini. Dermatol Online J. 2012;18:1-4.

7. Lee Y, Oh Y, Ahn SY, Park HY, Choi EH. A case of atrophoderma of Pasini and Pierini associated with Borrelia burgdorferi infection successfully treated with oral doxycycline. Ann Dermatol. 2011; 23:352-6.

8. Carter JD, Valeriano J, Vasey FB. Hydroxychloroquine as a treatment for atrophoderma of Pasini and Pierini. Int J Dermatol. 2006; 45:1255-6.

Copyright by Romita Bachaspatimayum, et al.. This is an open access article distributed under the terms of the Creative Commons Attribution License, which permits unrestricted use, distribution, and reproduction in any medium, provided the original author and source are credited.

Source of Support: Nil, Conflict of Interest: None declared. 